\title{
Immunomodulation by food: promising concept for mitigating allergic disease?
}

\author{
Harry Wichers
}

Received: 26 March 2009 /Revised: 30 April 2009 / Accepted: 4 May 2009 /Published online: 20 May 2009

(C) The Author(s) 2009. This article is published with open access at Springerlink.com

\begin{abstract}
The importance of a properly functioning and well-balanced immune system for maintaining health has become strikingly evident over the past decades. Roughly since World War II, there has been an apparent decrease in the prevalence of "traditional" infectious diseases, with a concomitant increase in immune-related disorders, such as allergies. Causally, a relationship with changes in lifestyle-related factors such as the increasing use of hygienic practices seems likely. Diet and nutrition can affect the functioning of various immune parameters. This concept can be utilised in attempts to prevent or mitigate allergic reactions via the development of targeted food products or ingredients. This review describes recent findings with respect to food products and ingredients that show potential in this respect, with special emphasis on pro- and prebiotics, $\beta$-glucans and fungal immunomodulatory proteins. What all of these approaches have in common is that they appear to strengthen Th1mediated immunity, thus possibly restoring defective immune maturation due to overly hygienic living conditions: a little bit of dirt does not seem bad!
\end{abstract}

Keywords Immunity · Immunomodulation · Allergy · Probiotics $\cdot$ Prebiotics $\cdot \beta$-Glucans

Fungal immunomodulatory proteins $\cdot$ Diet $\cdot$ Nutrition

H. Wichers $(\bowtie)$

Agrotechnology and Food Sciences Group,

Department of Cell Biology and Immunology,

Wageningen University and Research Centre,

PO Box 17, 6700 AA Wageningen, The Netherlands

e-mail: harry.wichers@wur.nl

\section{Introduction}

The importance of a properly functioning and wellbalanced immune system for maintaining health has become strikingly evident over the past few decades. There has been, roughly since World War II, an apparent decrease in the prevalence of "traditional" infectious diseases, such as tuberculosis, mumps, or measles, with a concomitant increase in immune-related disorders, such as multiple sclerosis, irritable bowel disease, type 1 diabetes and various allergic diseases. In addition, a "gradient" in disease incidence can be observed, decreasing in the north-south direction in the Northern Hemisphere, and vice versa in the Southern Hemisphere [1]. Such observations suggest a relationship with nongenetic factors, such as (changes in) health care and medical practice, (changes in) living environment and lifestyle, level of welfare, dietary habits, and the like. In particular, it has been hypothesised that the strong increases in rates of asthma and allergic disease are related to the increased use of hygienic practices and the subsequently reduced exposure to microbes, which supposedly results in an "undereducated" immune system [2]. This includes food hygienic practice, the tremendous virtues of which cannot be disputed, but which may have contributed to impaired or delayed immune maturation. Also, the rise in food products that are composed of highly refined ingredients has led to the decreased consumption of micronutrients, which may be relevant to immune maturation [3]. Interestingly, the incidence of tuberculosis was reported to be inversely related to the incidence of asthma and rhinoconjunctivitis, confirming the importance of a vigilant Th1 compartment in disease aetiology, as mycobacteria elicit particularly strong Th1 responses [4]. Not just in atopic disorders, but in many other chronic diseases - for instance cardiovascular 
diseases, neoplastic malformations, and metabolic syndrome-chronic inflammatory processes are involved, possibly causally, in the development of subsequent related health problems, also suggesting an important role for immune interventions [5-9]. The prophylactic and therapeutic relevance of immune modulation is confirmed by the possibility of developing antitumor strategies via vaccination, such as as has been described for Mycobacteriumbased vaccines and lung tumours, an effect supposedly based on selective enhancement of Th1-mediated immunity [10], and the claimed prophylactic effect of the Th1-stimulating mushroom-derived $\beta$-glucan lentinan on malaria [11], which all adds to the evidence that a better comprehension of and capacity to maintain immune homeostasis is of extreme importance to both individual and public health.

Immune modulation, for example via dietary strategies, may hold promise as well for maintaining immune homeostasis in the healthy population. Immunity, described as the activities of its various compartments, strongly varies throughout life. For instance, there is a decline in the functional capacity to elicit generalised and specific immune responses with increasing age, and regulatory cells show a decrease in production and response to regulatory signals. Overall, these developments result in the impairment with age of innate and adaptive immune responses, increased self-antigen reactivity, increased incidence of infection, and increased vulnerability to the development of neoplastic malformations. Overall, the implications of such immune phenomena associated with senescence are that susceptibility to specific health conditions may vary with age, with immune impairment eventually leading to increased risk of mortality [12-16]. Although still in its infancy, the use of dietary factors, notably vitamin $\mathrm{E}$ and $\omega$-3-PUFAs, as tools to circumvent this age-related decline in immune function is a focus of research [17].

\section{Dietary components and immunity}

The question "which food components impact on the functioning of specific immune compartments?" could perhaps better be phrased as "which food components do not have an impact on immune function?". Protein energy malnutrition (PEM), for instance, affects all aspects of immune function, with these effects being even more pronounced in the elderly. The functioning of T-cell and B-cell subsets and functions and of innate immunity are strongly related to protein nutritional status. Immune responses can be restored by relieving this protein shortage, but at a slower speed in patients that suffer from inflammatory processes. The imbalance between normal macrophage functions and decreased T-cell function is partly responsible for chronic inflammatory processes in vulnerable patients. Acute phase responses are, for these reasons, more detrimental to nutritional status and nutrient reserves in elderly patients than in adults [18, 19]. The dietary protein:carbohydrate ratio appears to be important in maintaining immune responsiveness; maintaining low protein and high carbohydrate levels for prolonged intervals seems to be beneficial, as evidenced in a rat model [20].

The concept of dietary components being of paramount importance to immune function is also tangible in the formulation of so-called immunonutrition, specific nutritional preparations for clinical use in critically ill patients with jeopardised immune function. Such preparations contain specific amino acids such as arginine and glutamine, nucleotides, and specific polyunsaturated fatty acids, notably $\omega-3$ PUFAs $[21,22]$.

Immune function is the target for the development of functional foods. In particular, vitamins, such as A, C, D and $\mathrm{E}$, and minerals as $\mathrm{Zn}$ and Se are focal points for this, next to PUFAs such as docosahexaenoic acid (22:6n-3; DHA) and eicosapentaenoic acid (20:5n-3; EPA). A detailed essay on the immunomodulatory properties of each of these nutrients is beyond the scope of this paper, so the reader is referred to a number of recent reviews and research papers that deal with these matters [21-26], and references therein. For a number of other nutrients and products, research is still in a less advanced stage - at the stage of in vitro or animal models at best - and some research issues in this field will be dealt with below.

Therefore, there seems to be a role for food and nutrition in supporting and maintaining immune homeostasis for various groups of individuals. It should be realised, however, that research into the possible role of functional foods in mitigating (human) immune function is still in its infancy, and that controversy around health claims will remain the rule rather than the exception so long as there is no improvement in (for example) the identification of suitable biomarkers, and in our comprehension of individual responses (genetics and imprinting) and the underlying physiological and biochemical mechanisms associated with nutrients.

The conclusion that modulating immune response may well serve as the basis for the development of functional foods appears at hand. Before such approach can achieve its full potential, however, it is essential to realise that functional foods should be regarded as food products with specific health benefits (above those of average consumption levels) for targeted groups of consumers. Therefore, the specific needs of individuals or groups of individuals must be matched with the immunomodulatory properties of specific products. Products that may be of benefit to, for example, allergic consumers do not necessarily have a beneficial effect on other consumers with different require- 
ments for immune mitigation; requirements for neonates likely differ from those of the elderly, and so on: one size does not fit all!

\section{Objective and rationale}

The objectives of the research area are to develop immunity-related markers for health effects of food, and to develop dietary or food products to support vital and balanced immune function throughout life.

Immunological read-outs are used to determine possible health effects because:

- A variety of chronic health threats that have an enormous economic impact and also impact on quality of life are directly related to immune function, such as autoimmune diseases, allergies and asthma, and immune deficiencies.

- The immune system plays a role in the pathology of chronic and age-related anomalies; in some cases a causal one (or perhaps only partially so).

- There is increasing evidence (from randomised doubleblind intervention studies and clinical trials too) of the capacity of food components to modulate the response of the immune system, both positively (immunepotentiating) and negatively (e.g. food allergy).

The analysis of the capacity and activity of the immune system offers advantages that may facilitate the translation from an experimental setting to possible application and implementation, because of the pivotal role of the immune system that has been acknowledged in health analysis and clinical practice:

- For many immune functions, diagnostically validated in vitro or in vivo test systems are available

- For many immune functions, animal models and cell lines for in vitro analysis are available

- The role of the immune system in clinical practice and the pathology of many chronic anomalies is relatively well documented.

- There is an increased interest in linking individual immune reactivity to lifestyle- and age-associated factors, where food and nutrition show the best documented effects.

The current lack of mechanistic underpinning of the health effects of food intake results in sometimes contradictory claims and statements, confusion, and a loss of trust and confidence amongst consumers. Addressing this lacuna will contribute to a solid basis for health claims, and consequently to the concept of "health promotion via nutrition". Immune modulation offers unique perspectives for meeting such requirements.

\section{Types of products with immunomodulatory claims that are currently on the market}

Despite the relative infancy of the state of scientific understanding of interactions between immunity, food and diet at present, there are already a number of products on the market for either clinical, food or feed-related applications. Since this paper is not an "advertorial", no specific products will be mentioned, but some product groups with more or less specific applications will be indicated:

- “Immunonutrition". Immunonutrition-type products are typically meant for clinical use for critically ill or surgical patients, to fortify hampered immune function. Application routes can be either parenteral or enteral; the optimal route may depend on patient and disease characteristics. Typical components included in such products are specific amino acids (notably glutamine and arginine), nucleotides, $\omega-3$ PUFAs, minerals such as $\mathrm{Zn}$ and $\mathrm{Se}$, and various compounds with antioxidative properties [21-31]. Since immunonutrition is used in relatively well-described clinical cases, with relatively well-defined end-points, there is a rather wellelaborated scientific basis for its application.

- Pro- and prebiotics. Probiotics are, by definition, "nonpathogenic microorganisms that when given in adequate numbers exert beneficial effects on the host", whereas prebiotics are a category of functional food defined as "nondigestible food ingredients that beneficially affect the host by selectively stimulating the growth and/or activity of one or a limited number of bacteria in the colon, and thus improve host health" [32]. A number of beneficial health effects have been claimed for the pro-pre-biotic product category, including effectiveness against antibiotic-associated or travellers diarrhoea, improved stools, as well as an array of immunity-related health claims, also in relation to allergic disease.

Fructose oligosaccharide and galactose oligosaccharide fortified infant formulas are currently on the market; these are intended to support the developing immune systems of neonates (see below for more detail, and [33] for an extensive review of various health-related claims).

- Hypoallergenic infant formulas. A product category that has the immunomodulatory property that it does not activate a potentially anomalously reacting immune response. Hydrolysed preparations of milk proteins are in the market, and these are aimed in particular at circumventing clinical reactions in individuals allergic to cow's milk. The degree of protection is usually quite good, and dependent on the degree of hydrolysis [34]. 
Again, this concerns a category of relatively welldefined patients with a relatively well-understood clinical history.

- $\beta$-Glucan-containing preparations for feed applications. In an attempt to limit the use of antibiotics in animal husbandry, spent brewer's yeast is added to feed in order to increase natural resistance. This effect is attributed to $\beta$-glucans, which are present in yeast cell walls, and are supposed to interfere with and enhance immunity (see e.g. [35]). Preparations that claim an enhanced accessibility of $\beta$-glucans to the immune system are even marketed.

- Various supplements. A plethora of various kinds of food supplements are available on the market, which are too large in number and too variable in composition (if they can be defined at all) to be discussed comprehensively here. However, they often have a common denominator, in the sense that there is only very meagre underpinning of claims, and indications of who should or could take such preparations and when are scarce.

\section{Research into immunomodulation by food, with a focus on allergy}

\section{Probiotics}

Probiotic bacteria are nonpathogenic microorganisms that are thought to exert positive health effects on the host. In by far the majority of cases, Lactobacillus or Bifidobacterium spp. are the microorganisms endowed with the supposed beneficial effects; nevertheless, it should be noted that the distinction between "good" and "bad" organisms is a rather arbitrary one, and is strongly dependent on where in the digestive tract, and to whom, they are applied [36]. Some years ago, relationships between the composition of intestinal microbiota and the occurrence and incidence of allergic diseases were noted [37-39]. In particular, a comparison between Estonian and Swedish school children demonstrated that allergic children were less often colonised with Lactobacilli and more often with aerobic coliforms and Staphylococcus aureus [37, 38], or lower Bifidobacterium counts and higher Clostridium colonisation numbers were found [39]. This was supposed to be relevant to the proper maturation of intestinal immunity, and in particular to impact on the balance between Th1 and Th2 cells [38, 39], thus suggesting options for nutritional and dietary intervention, via probiotics, for this type of condition.

Indeed, when Lactobacilli (LGG) was given to 159 pregnant women (at risk of allergy) for two weeks and to their babies for six months, $50 \%$ fewer infants in the LGG group than in the placebo group demonstrated atopic eczema at two years of age [40]. Similarly, LGG and Bifidobacterium lactis $\mathrm{Bb} 12$ were shown to decrease the severity of atopic eczema [41]. In a similar study, serum tolerance-related cytokine IL-10 was elevated significantly in the LGG group [42]. Furthermore, administering L. casei Shirota was found to significantly suppress the production of IL-5, IL- 6 and IFN- $\gamma$ compared to placebo in PBMCs of (adult) sufferers from seasonal allergic rhinitis [43]. However, results sometimes were reproducible elsewhere [44], or they were not, e.g. in the development of atopic dermatitis [45]. Also, in a group of teenagers and young adults, the application of Lactobacillus rhamnosis did not alleviate birch-pollen allergy symptoms [46]. Furthermore, dietary LGG supplementation a few weeks before delivery did not appear to have an effect on the proliferative response of PBMCs from atopic or control neonates, thus suggesting that there was no impact on sensitisation potential [47].

In conclusion, results in allergy prevention are still variable and heavily debated. In vitro observations suggest that a possible mechanism for positive effects on allergyrelated immunity is the restoration of imbalances between various T-cell subsets, perhaps indirectly via TLR signalling in innate immune cells. In vivo results may be strongly strain dependent, as a variety of immune effects, e.g. IL-10 inducing (tolerance enhancing?) or Th1 skewing, may be observed during the in vitro screening of probiotic strain collections [Vissers et al., publications in preparation]. However, effects on gut permeability or intestinal allergen processing cannot be excluded. Also, responses may depend on individual patient characteristics as well, such as whether allergies have already fully developed or not. Recently, interactions between (inducible) Lactobacillus Slayer protein and gut DCs were described that may contribute to the mechanism of action [48], primarily in relation to innate immunity.

In addition to allergic disease, probiotics are being investigated in for example celiac disease, gastroenteritis, IBD, colon and colorectal cancer, and antibiotic-associated diarrhoea [33].

However, above all, the conclusion is that stringent requirements for experimental design are imperative to avoid contradictory data, and to further this promising area of research.

\section{$\beta$-Glucans}

$\beta-(1 \rightarrow 3)-(1 \rightarrow 6)-G l u c a n s$ are rather ubiquitous polymers of glucose with a $\beta-(1 \rightarrow 3)$ backbone and $\beta-(1 \rightarrow 6)$ crosslinks, with typical $M r$ values in the range of several hundreds of $\mathrm{kDa}$, indicating $D p$ values of several thousands of glucose 
units, and are the subject of research in relation to their anticipated effects on immunity, in particular via binding to cells from the innate immune compartment such as macrophages and to NK cells $[47,48]$. This type of glucan can be found in bacteria, yeasts, fungi [51], seaweed [52] and cereals (the latter mainly containing $(1 \rightarrow 4)$ crosslinks [53]).

Kimura et al. described a mitigating effect of (orally administered) $\beta$-glucans on food allergic reactions in mouse models. Adding $0.5-1.0 \%$ of a $\beta$-glucan from Aureobasidium pullulans strain A1 to the diet of ovalbumin-allergic Balb/C mice considerably reduced ovaspecific IgE and stimulated IL-4, IFN- and IL-12 production in ConA-stimulated splenocytes from the mice [54]. Oral application of finely dispersed shiitake $\beta$-glucan (lentinan) in human patients allergic to cedar pollen significantly alleviated the symptoms of Japanese cedar pollen-induced rhinitis, sneezing, nasal congestion, and conjunctivitis, and its oral uptake before symptom onset exhibited preventive effects. Allergic symptoms were relieved not only for seasonal allergies to cedar pollen but also for perennial allergies. Oral ingestion of $\beta-(1 \rightarrow 3)$ glucan in individuals with allergic tropism could reduce the spontaneous increase in both allergen-specific and total $\operatorname{IgE}$ titers, and the clinical responses to treatment were well correlated with the capacity of monocytes to bind to $\beta$ $(1 \rightarrow 3)$-glucan [55]. Both the route of application (nasal application of $\beta$-glucans, resulting in the glucans acting as an allergen [54]) and the degree of dispersion appeared important, as nondispersed lentinan did not give the desired effects [55].

Similar (peanut) allergy relieving effects were observed in $\mathrm{C} 3 \mathrm{H} / \mathrm{HeJ}$ mice, for an orally applied complex herbal preparation in which $\beta$-glucans (from the fungus Ganoderma lucidum) were undoubtedly present [56]. Also, again orally applied, G. lucidum preparations were effective in a mouse model for house dust mite allergy [57].

$\beta$-Glucans appear to exert their immunomodulatory effects via the activation of innate pathways, e.g. in macrophages $([49,50]$ Fig. 1). $\beta$-Glucans were found to stimulate the production of TNF- $\alpha$, IFN- $\gamma$ and IL-12 when injected into ICR mice [58], as was also found in models of human peripheral blood mononuclear cells in which various fungal extracts were screened [59], although there is also a report that shows a somewhat different picture for Aureobasidium pullulans; in that report, IL-8 production in PBMCs and in a monocyte cell line was detected [60]. Activation of T-cells in PBMC cultures is probably an indirect effect of the stimulation of innate cells, and reaction cascades may depend on typical characteristics of $\beta$-glucans such as $\mathrm{Mr}$ (the Aureobasidium glucan being relatively small, ca. $100 \mathrm{kDa}$, and highly branched (50$80 \%$ ) [54]), which can perhaps account for (some of) the differences in observations. A number of receptors for $\beta$ - glucans (dectin-1, complement receptor 3, TLR2 and TLR6, scavenger receptors and lactosylceramide) have been described. Dectin-1 is particularly commonly expressed on immune cells, such as dendritic cells, macrophages, monocytes, neutrophils, eosinophils, some T-cells and in humans on B-cells too. The possible expression of dectin-1 on intestinal cells is under debate [49]. The interaction of dectin- 1 and TLR2 upon $\beta$-glucan binding leads to synergistic effects on the production of cytokines such as TNF- $\alpha$ and IL12, a process in which NF-kB [59] and spleen tyrosine kinase are claimed to be involved [62].

Receptor binding studies in which the Ig-labelled polysaccharide-binding domains of dectin-1 were used to detect glucan binding have demonstrated that dectin-1 preferentially binds to the $\beta-(1 \rightarrow 3)$ part of the glucan, and that the minimal length required to allow binding to dectin-1 is $10-11$ glucose residues [63]. It should be realised that these observations were derived from an abstracted experimental model, leaving the physiological significance of the $\beta-(1 \rightarrow 6)$-branches as yet unanswered. As the binding of $\beta$-glucans to dectin and TLR-2 shows synergistic effects, perhaps there is a role for the $\beta-(1 \rightarrow 6)$ -

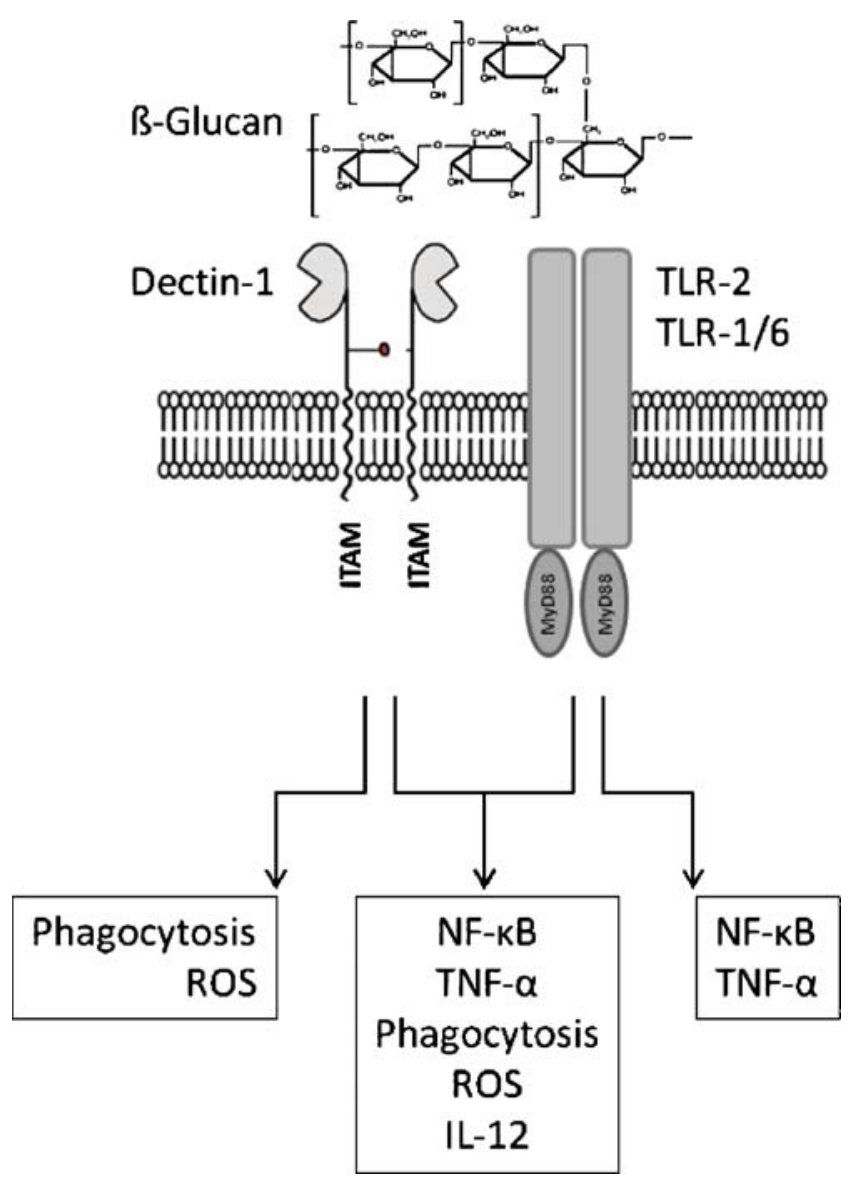

Fig. 1 Conceptual model for the interaction between $\beta$-glucans and innate immune receptors as expressed on macrophages. Interaction between dectin-1 and the TLRs leads to synergistic responses 
branched structure in this effect [61]. Single-chain $\beta$ glucans appear to induce stronger responses (NF-kB, iNO production, $\mathrm{TNF}-\alpha$ ) in (murine) macrophages than oligomeric chains do [50]. Increasing the solubility of $\beta$-glucans, for instance by preparing sulfated, carboxymethylated, methylated, hydroxyethylated or hydroxypropylated derivatives, increased their activity against Sarcoma-180 tumour cells [64], the effectiveness of which in relation to allergy mitigation can only be speculated on.

Taken altogether, there appear to be clear indications, from both animal models and from a human study, that orally applied $\beta$-glucans or glucan-containing preparations can be of help for relieving various allergy-related symptoms. Applications of Th1 stimulation are anticipated not only in allergy mitigation but also in the stimulation of cell-mediated immunity and increased infection resistance. It appears as if these compounds activate (indirectly via primary innate activation) Th1-mediated immunity, primarily via activation through TLR/CLR (dectin) signalling.

More details on their mode of action, such as for instance how and where interactions between $\beta$-glucans and immune cells take place (via intestinal microfold-(M-) cells? Via, into the intestinal lumen protruding, dendritic cells? Transport via tight junctions (para-cellular transport), as well as structure-function studies and research on application and delivery methods, for instance incorporation into food products or supplements, will be essential to further develop this promising research direction.

Fungal immunomodulatory proteins (FIPs)

FIPs are $15 \mathrm{kDa}$ proteins of (as far as we are aware so far) fungal origin. A number of FIPs have been described in some detail, including those from Flammulina velutipes (golden needle mushroom; FIP-fve), Volvariella volvacea ((paddy) straw mushroom; FIP-vvo), Ganoderma lucidum and G. tsugae (Japanese lacquer mushroom; LZ8 and FIP-gts, resp.), which are composed of 114 (FIP-fve), 110 (LZ-8 and FIP-Gts) and 112 (FIP-vvo) amino acids, respectively, and share high sequence homology ([65] and Fig. 2). FIP-fve was crystallised and its X-ray structure determined $[65,66]$; it was found to be a homodimer where each subunit comprises a pair of $\mathrm{N}$-terminal secondary structural elements, an $\alpha$-helix followed by a $\beta$-strand linked to a domain consisting almost exclusively of $\beta$ sheets adopting an Ig-like fold, with $\alpha$-helix, $\beta$-strand and loop fractions of respectively $11.3,42.6$ and $46.1 \%$ [66]. The $\alpha$-helices $\mathrm{H}_{\mathrm{A}}$ and $\mathrm{H}_{\mathrm{B}}$ are amphipathic and the side chains of the amino acids on the hydrophobic face of one helix pack well against those of the other $\alpha$-helix, enabling them to bind via hydrophobic interactions. Lin et al. [68] predicted that the N-terminal residues $1-13$ of FIP-Gts formed an $\alpha$-helix, and they found that recombinant mutants of FIP-Gts in which residues 1-13 (the Nterminal $\alpha$-helix) were deleted were incapable of dimerisation. Triple mutants in which Leu5, Phe7 and Leu9 were deleted lost their amphipathic character, the ability to form dimers with themselves and with the wild-type FIPGts protein, suggesting that this property was important for immunomodulatory activity $[67,68]$. FIPs show lectinlike properties, as they are able to agglutinate erythrocytes, and it was suggested that they should be classified as such [67].

The biological relevance of FIPs for allergy mitigation lies in the observation that they were able to inhibit foodallergic and respiratory-allergic reactions in mouse models when applied orally or nasally. When fed (at $200 \mathrm{mcg} /$ mouse, i.e. ca. $4 \mathrm{mg} \mathrm{kg}^{-1}$, every other day) to ovalbuminallergic Balb/c-mice, allergy symptoms (symptom score, histamine release, intestinal damage) were strongly suppressed, and the Th2-dominant phenotype shifted towards a strongly elevated Th1 response (measured in splenocytes) upon FIP feeding, showing its potential in allergy prophylaxis [69]. Liu et al. found that FIP-fve could be applied in local nasal immune therapy to suppress allergic responses to house dust mite allergy in Balb/c mice [70], and a shift in cytokine profile towards a stronger Th1-response was also noted in this study.

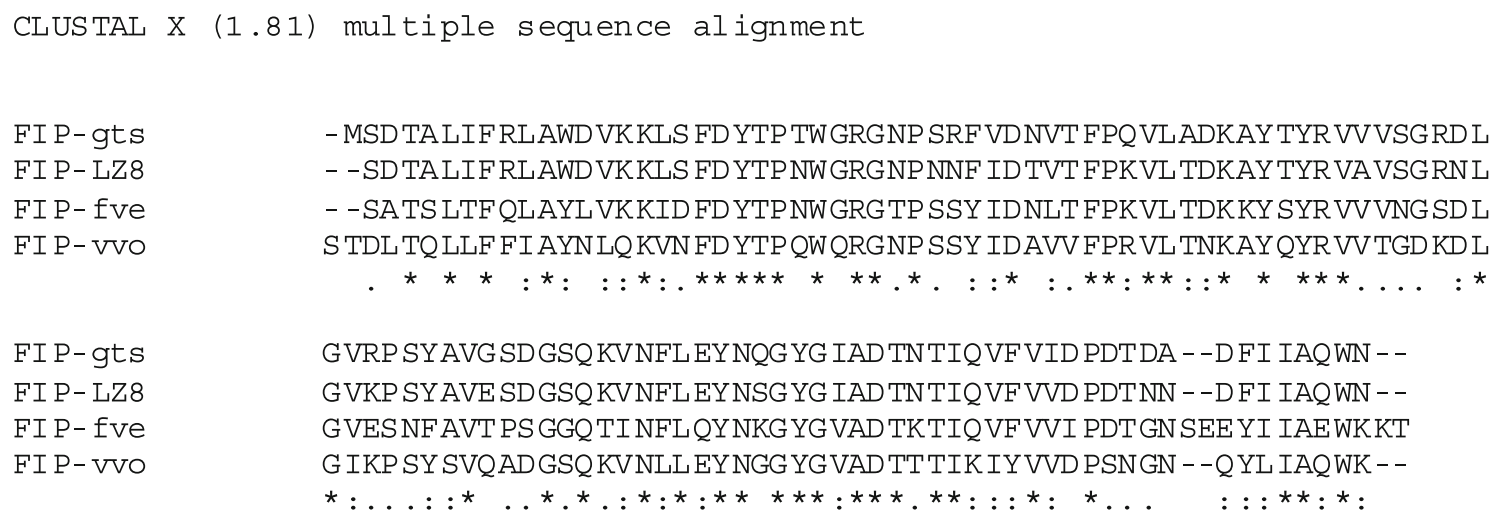

Fig. 2 Sequence alignment of FIPs from various sources, demonstrating homology; see text 
Not many details on the putative mode of action of FIPs have been published, other than that FIP-fve appeared to stimulate IFN- $\gamma$ production in human PBMCs via $\mathrm{p} 38$ MAPK activation [71]. Our own observations ([72], and unpublished results) indicate that natural FIPs or cloned FIPs from Flammulina or Ganoderma have a limited effect on NO production in RAW 264.7 cells (a murine monocyte cell line), and a Th1-skewing effect in human PBMC cultures from healthy volunteers. This was partly corroborated by observations for a immunomodulatory protein from Auricularia (Jew's ear) mushroom, a protein that perhaps (although this is not yet confirmed) should also be considered a FIP, of Th1 skewing but not NO production in RAW 264.7 cells [73].

One interesting aspect, considering their potential application as food-derived immunomodulatory compounds, is the apparent resistance of the biological activity of these FIPs to common food processing conditions, such as freezing, thawing, dehydration, and acid/alkali conditions $[74,75]$.

Questions as to their digestion stability, and on the signalling mechanisms (again: absorption via tight junctions (para-cellular transport), DCs, M-cells, signalling via GALT?) remain to be answered.

\section{Perspectives}

Based on the above, the option of immunomodulation via diet appears to be a realistic option, with advantages for specific immune-related conditions such as allergies at the very least, although perhaps also in other application areas too, such as in maintaining immune homeostasis and vigilance. Considering the pivotal role of immune homeostasis in general health, and the very relevant and significant societal and economic perspectives, this research avenue seems to be a very worthwhile one, to say the least. It appears as if different food components can exhibit effects on specific immune compartments, thus offering the potential for use in a variety of applications, depending on the characteristics of the deviating chronic processes and the characteristics of the consumers or patients. Foods can thus play a significant role in fortifying and balancing immune responses.

As it becomes more and more clear that the aetiology and course of a given "disease" varies from person to person, it also appears increasingly obvious that treatments (or, if possible and appropriate, supportive dietary measures) should be tuned more towards individual needs. This means that, in the "functional foods" domain, uniform approaches will probably not be maximally effective, thus emphasising the need for greater knowledge on individual consumer's responses and the (deviations in) metabolism that underlie the development of chronic anomalies. This may not be a nice message for food producers, because markets may fragment, but so be it; once more insight into the underlying mechanisms has been obtained, a better perspective on the chances of product development will be obtained.

With respect to the impact of immunomodulatory foods and food components on allergic reactions, as described in this manuscript, it is striking that in all of the described cases, a skewing of cytokine profiles from Th2 dominance towards a more rebalanced state (read: an enhanced Th1 response) was observed. Secondly, in all cases the active products or ingredients were microorganisms or products derived from them. This leads to the hypothesis that, if indeed an overly hygienic living environment and lifestyle is the basis for the increase in allergic reactions, this situation can perhaps be (partly) restored by exposure to specific microbial constituents, likely activating innate immunity and subsequently skewing adaptive immunity towards a strengthened cell-mediated response: a little bit of dirt does not seem to be bad!

Open Access This article is distributed under the terms of the Creative Commons Attribution Noncommercial License which permits any noncommercial use, distribution, and reproduction in any medium, provided the original author(s) and source are credited.

\section{References}

1. Bach JF (2002) The effect of infections on susceptibility to autoimmune and allergic diseases. New Engl J Med 347:911-920

2. Strachan DP (1989) Hay fever, hygiene, and household size. Br Med J 299(6710):1259-1260

3. Rowbotham J, Clayton P (2008) An unsuitable and degraded diet? Part three: Victorian consumption patterns and their health benefits. J R Soc Med 101:454-462

4. Von Mutius E, Pearce N, Beasley R, Cheng S, Von Ehrenstein O, Björkstén B, Weiland S (2000) International patterns of tuberculosis and the prevalence of symptoms of asthma, rhinitis, and eczema. Thorax 55:449-453

5. Kabingu E, Vaughan L, Owczarczak B, Ramsey KD, Gollnick SO (2007) CD8+ T cell-mediated control of distant tumours following local photodynamic therapy is independent of CD4+T cells and dependent on natural killer cells. Br J Cancer 96:1839-1848

6. Valdés-Ramos R, Benítez-Arciniega AD (2007) Nutrition and immunity in cancer. Br J Nutr 98(Suppl 1):S127-S132

7. Oda E (2008) The metabolic syndrome as a concept of adipose tissue disease. Hypertens Res 31(7):1283-1291

8. Després JP, Lemieux I (2006) Abdominal obesity and metabolic syndrome. Nature 444(7121):881-887

9. Wisse BE (2004) The inflammatory syndrome: the role of adipose tissue cytokines in metabolic disorders linked to obesity. J Am Soc Nephrol 15(11):2792-2800

10. Grange JM, Bottasso O, Stanford CA, Stanford JL (2008) The use of mycobacterial adjuvant-based agents for immunotherapy of cancer. Vaccine 26(2008):4984-4990 
11. Zhou L-D, Zhang Q-H, Zhang Y, Liu J, Cao Y-M (2009) The shiitake mushroom-derived immuno-stimulant lentinan protects against murine malaria blood-stage infection by evoking adaptive immune-responses. Int Immunopharmacol 9(4):455-462

12. Burns EA, Goodwin JS (2004) Effects of aging on immune function. J Nutr Health Ageing 8(1):9-18

13. Derhovanessian E, Solana R, Larbi A, Pawelec G (2008) Immunity, ageing and cancer. Immunity Ageing 5:11. doi:10.1186/1742-4933-5-11

14. Gardner EM, Murasko DM (2002) Age-related changes in Type 1 and Type 2 cytokine production in humans. Biogerontology 3:271-289

15. Gorczynski RM, Terzioglu E (2008) Aging and the immune system. Int Urol Nephrol 40(4):1117-1125

16. Srivastava S, Lundqvist A, Childs R (2008) Natural killer cell immunotherapy for cancer: a new hope. Cytotherapy 10(8):775783

17. Meydani SN, Wu D (2007) Age-associated inflammatory changes: role of nutritional intervention. Nutr Rev 65(12 Pt 2):S213-S216

18. Lesourd B (2004) Nutrition: a major factor influencing immunity in the elderly. J Nutr Health Aging 8(1):28-37

19. Keusch GT (2003) The history of nutrition: malnutrition, infection and immunity. J Nutr 133(1):336S-340S

20. Pal S, Poddar K (2008) Dietary protein-carbohydrate ratio: exogenous modulator of immune response with age. Immunobiol 213:557-566

21. Calder PC (2007) Immunonutrition in surgical and critically ill patients. Br J Nutr 98(S1):S133-S139

22. Fernandes G (2008) Progress in nutritional immunology. Immunol Res 40:244-261

23. Harbige LS (1996) Nutrition and imunity with emphasis on infection and autoimmune disease. Nutr Health 10:285-312

24. Calder PC, Kew S (2002) The immune system: a target for functional foods? Br J Nutr 88:S165-S176

25. López-Varela S, González-Gross M, Marcos A (2002) Functional foods and the immune system: a review. Eur J Clin Nutr 56(S3): S29-S33

26. Hoyles L, Vulevic J (2008) Diet, immunity and functional foods. Adv Exp Med Biol 635:79-92

27. Meydani SN, Wu D (2008) Nutrition and age-associated inflammation: implications for disease prevention. J Parent Ent Nutr 32 (6):626-629

28. Meydani SN, Wu D (2007) Age-associated inflammatory changes: role of nutritional intervention. Nutr Rev 65(12):S213-S216

29. Wu D, Meydani SN (2008) Age-associated changes in immune and inflammatory responses: impact of vitamin $\mathrm{E}$ intervention. $\mathrm{J}$ Leukoc Biol (accepted). doi:10.1189/jlb.0108023

30. Plat J, Mensink RP (2005) Food components and immune function. Curr Op Lipidol 16:31-37

31. Wintergerst ES, Maggini S, Hornig DH (2007) Contribution of selected vitamins and trace elements to immune function. Ann Nutr Metab 51:301-323

32. Gibson GR, Roberfroid MB (1995) Dietary modulation of the human colonic microbiota: introducing the concept of prebiotics. $\mathrm{J}$ Nutr 125(6):1401-1412

33. De Vrese M, Schrezenmeir J (2008) Probiotics, prebiotics, and synbiotics. Adv Biochem Eng Biotechnol 111:1-66

34. Fritsché R (2003) Animal models in food allergy: assessment of allergenicity and preventive activity of infant formulas. Toxicol Lett 140-141:303-309

35. Kogan G, Kocher A (2007) Role of yeast cell wall polysaccharides in pig nutrition and health protection. Livestock Sci 109 (1):161-165

36. Besselink MG, van Santvoort HC, Buskens E, Boermeester MA, van Goor H, Timmerman HM, Nieuwenhuijs VB, Bollen TL, van Ramshorst B, Witteman BJ, Rosman C, Ploeg RJ, Brink MA,
Schaapherder AF, Dejong CH, Wahab PJ, van Laarhoven CJ, van der Harst E, van Eijck CH, Cuesta MA, Akkermans LM, Gooszen HG, Dutch Acute Pancreatitis Study Group (2008) Probiotic prophylaxis in predicted severe acute pancreatitis: a randomised, double-blind, placebo-controlled trial. Lancet 371(9613):651-659

37. Bjorksten B, Naaber P, Sepp E, Mikelsaar M (2000) The intestinal microflora in allergic Estonian and Swedish 2-year-old children. Clin Exp Allergy 29(3):342-346

38. Bottcher MF, Nordin EF, Sandin A, Midtvedt T, Bjorksten B (2000) Microflora-associated characteristics in faeces from allergic and nonallergic infants. Clin Exp Allergy 30(11):1590-1596

39. Kalliomäki M, Kirjavainen P, Eerola E, Kero P, Salminen S, Isolauri E (2001) Distinct patterns of neonatal gut microflora in infants in whom atopy was and was not developing. J Allergy Clin Immunol 107(1):129-134

40. Kalliomäki M, Salminen S, Poussa T, Arvilommi H, Isolauri E (2003) Probiotics and prevention of atopic disease: 4-year followup of a randomised placebo-controlled trial. Lancet 361 (9372):1869-1871

41. Isolauri E, Arvola T, Sütas Y, Moilanen E, Salminen S (2000) Probiotics in the management of atopic eczema. Clin Exp Allergy 30(11):1604-1610

42. Pessi T, Sütas Y, Hurme M, Isolauri E (2000) Interleukin-10 generation in atopic children following oral Lactobacillus rhamnosus GG. Clin Exp Allergy 30(12):1804-1808

43. Ivory K, Chambers SJ, Pin C, Prieto Arqués EJL, Nicoletti C (2008) Oral delivery of Lactobacillus casei Shirota modifies allergen-induced immune responses in allergic rhinitis. Clin Exp Allergy 38:1282-1289

44. Rosenfeldt V, Benfeldt E, Nielsen SD, Michaelsen KF, Jeppesen DL, Valerius NH (2003) Paerregaard A (2003) Effect of probiotic Lactobacillus strains in children with atopic dermatitis. J Allergy Clin Immunol 111(2):389-395

45. Brouwer ML, Wolt-Plompen SA, Dubois AE, van der Heide S, Jansen DF, Hoijer MA, Kauffman HF, Duiverman EJ (2006) No effects of probiotics on atopic dermatitis in infancy: a randomized placebo-controlled trial. Clin Exp Allergy 36(7):899-906

46. Helin T, Haahtela S, Haahtela T (2002) No effect of oral treatment with an intestinal bacterial strain, Lactobacillus rhamnosus (ATCC 53103), on birch-pollen allergy: a placebo-controlled double-blind study. Allergy 57(3):243-246

47. Kopp MV, Goldstein M, Dietschek A, Sofke J, Heinzmann A, Urbanek R (2008) Lactobacillus GG has in vitro effects on enhanced interleukin-10 and interferon-gamma release of mononuclear cells but no in vivo effects in supplemented mothers and their neonates. Clin Exp Allergy 38(4):602-610

48. Konstantinov SR, Smidt H, de Vos WM, Bruijns SC, Singh SK, Valence F, Molle D, Lortal S, Altermann E, Klaenhammer TR, van Kooyk Y (2008) (2008) S layer protein A of Lactobacillus acidophilus NCFM regulates immature dendritic cell and T cell functions. Proc Natl Acad Sci USA 105(49):19474-19479

49. Volman JJ, Ramakers JD, Plat J (2008) Dietary modulation of immune function by beta-glucans. Physiol Behav 94(2):276-284

50. Kataoka K, Muta T, Yamazaki S, Takeshige K (2002) Activation of macrophages by linear $(1 \rightarrow 3)-\beta$-D-glucans. J Biol Chem 277 (39):36825-36831

51. Schepetkin IA, Quinn MT (2006) Botanical polysaccharides: macrophage immunomodulation and therapeutic potential. Int Immunopharmacol 6:317-333

52. Vetvicka V, Dvorak B, Vetvickova J, Richter J, Krizan J, Sima P, Yvin J-C (2007) Orally administered marine $(1 \rightarrow 3)-\beta$-D-glucan Phycarine stimulates both humoral and cellular immunity. Int $\mathrm{J}$ Biol Macromol 40:291-298

53. Muralikrishna G, Subba Rao MVSST (2007) Cereal noncellulosic polysaccharides: structure and function relationshipan overview. Crit Rev Food Sci Nutr 47(6):599-610 
54. Kimura Y, Sumiyoshi M, Suzuki T, Suzuki T, Sakanaka M (2007) Inhibitory effects of water-soluble low-molecular-weight $\beta$-(1, 3-1, 6)-D-glucan purified from Aureobasidium pullulans GM-NH-1A1 strain on food allergic reactions in mice. Int Immunopharmacol 7:963-972

55. Yamada J, Hamuro J, Hatanaka H, Hamabata K, Kinoshita S (2007) Alleviation of seasonal allergic symptoms with superfine $\beta$-1, 3-glucan: a randomized study. J Allergy Clin Immunol 119:1119-1126

56. Li XM, Zhang TF, Huang CK, Srivastava K, Teper AA, Zhang L, Schofield BH, Sampson HA (2001) Food Allergy Herbal Formula-1 (FAHF-1) blocks peanut-induced anaphylaxis in a murine model. J Allergy Clin Immunol 108:639-646

57. Liu Y-H, Tsai C-F, Kao M-C, Lai Y-L, Tsai JJ (2003) Effectiveness of Dp2 nasal therapy for Dp-2 induced airway inflammation in mice: using oral Ganoderma lucidum as an immunomodulator. J Microbiol Immunol Infect 36:236-242

58. Tada R, Tanioka A, Iwasawa H, Hatashima K, Shoji Y, Ishibashi K-I, Adachi Y, Yamazaki M, Tsubaki K, Ohno N (2008) Structural characterisation and biological activities of a unique type $\beta$-Dglucan obtained from Aureobasidium pullulans. Glycoconj J 25 (9):851-861

59. Lull-Noguera C, Wichers HJ, Savelkoul HFJ (2005) Antiinflammatory and immuno-modulating properties of fungal metabolites. Mediat Inflamm 2005(2):63-80

60. Ikewaki N, Fujii N, Onaka T, Ikewaki S, Inoko H (2007) Immunological actions of Sophy $\beta$-glucan $(\beta-1,3-1,6$ glucan), currently available commercially as a health food supplement. Microbiol Immunol 51(9):861-873

61. Meyer-Wentrup F, Cambi A, Adema GJ, Figdor CG (2005) "Sweet talk": closing in on C type lectin signaling. Immunity 22:399-400

62. Brown GD (2006) Dectin-1: a signalling non-TLR patternrecognition receptor. Nature Rev Immunol 6:33-43

63. Palma AS, Feizi T, Zhang Y, Stoll MS, Lawson AM, DiazRodriguez E, Campanero-Rhodes MA, Costa J, Gordon S, Brown GD, Chai W (2006) Ligands for the $\beta$-glucan receptor, dectin-1, assigned using "designer" microarrays of oligosaccharide probes (neoglycolipids) generated from glucan polysaccharides. J Biol Chem 281:5771-5779

64. Wang Y, Zhang L, Li Y, Hou X, Zeng F (2004) Correlation of structure to antitumor activities of five derivatives of a $\beta$-glucan from Poria cocos sclerotium. Carb Res 339:2567-2574
65. Hsu H-C, Hsu C-I, Lin R-H, Kao C-L, Lin J-Y (1997) Fip-vvo, a new fungal immunomodulatory protein isolated from Volvariella volvacea. Biochem J 323:557-565

66. Seow SV, Kuo I-C, Paaventham P, Kolatkar PR, Chua KY (2003) Crystallisation and preliminary $\mathrm{X}$-ray crystallographic studies on the fungal immunomodulatory protein Fve from the golden needle mushroom (Flammulina velutipes). Acta Crystallog 59:1487-1489

67. Paaventhan P, Jospeh JS, Seow SV, Vaday S, Robinson H, Chua KY, Kolatkar PR (2003) A $1.7 \AA$ structure of fve, a member of the new fungal immunomodulatory protein family. J Mol Biol 322:461-470

68. Lin WH, Hung CH, Hsu CI, Lin JY (1997) Dimerization of the Nterminal amphiphatic $\alpha$-helix domain of the fungal immunomodulatory protein from Ganoderma tsugae (Fip-gts) defined by a yeast two-hybrid system and site-directed mutagenesis. J Biol Chem 272:20044-20048

69. Hsieh KY, Hsu CI, Lin JY, Tsai CC, Lin RH (2003) Oral administration of an edible-mushroom-derived protein inhibits the development of food-allergic reactions in mice. Clin Exp Allergy 33:1595-1602

70. Liu Y-H, Kao M-C, Lai Y-L, Tsai J-J (2003) Efficacy of local nasal immunotherapy for Dp2-induced airway inflammation in mice: using Dp2-peptide and fungal immunomodulatory peptide. J Allergy Clin Immunol 112(2):301-310

71. Wang PH, Hsu CI, Tang SC, Huang YL, Lin JY, Ko JL (2004) Fungal immunomodulatory protein from Flammulina velutipes induces interferon- $\gamma$ production through p38 mitogen-activated protein kinase signaling pathway. J Agric Food Chem 52:2721-2725

72. Jeurink PV, Lull-Noguera C, Savelkoul HFJ, Wichers HJ (2008) Immunomodulatory capacity of fungal proteins on the cytokine production of human peripheral blood mononuclear cells. Int Immunopharmacol 8(8):1124-1133

73. Sheu F, Chien P-J, Chien A-L, Chen Y-F, Chin K-L (2004) Isolation and characterization of an immunomodulatory protein (APP) from the Jew's Ear mushroom Auricularia polytricha. Food Chem 87(4):593-600

74. Chang H-H, Chien P-J, Tong M-H, Sheu F (2007) Mushroom immunomodulatory proteins possess potential thermal/freezing resistance, acid/alkali tolerance and dehydration stability. Food Chem 105:597-605

75. Tong M-H, Chien P-J, Chang H-H, Tsai M-J, Sheu F (2008) High processing tolerances of immunomodulatory proteins in Enoki and Reishi mushrooms. J Agric Food Chem 56:3160-3166 